\title{
Ti3AlC2 coatings deposited by liquid plasma spraying
}

\author{
Haicheng Yu, Xinkun Suo, Yongfeng Gong, Yuejin Zhu, Jie Zhou, Hua Li, Per Eklund and \\ Qjng Huang
}

\section{Linköping University Post Print}

\section{Tweet}

N.B.: When citing this work, cite the original article.

Original Publication:

Haicheng Yu, Xinkun Suo, Yongfeng Gong, Yuejin Zhu, Jie Zhou, Hua Li, Per Eklund and Qjng Huang, Ti3AlC2 coatings deposited by liquid plasma spraying, 2016, Surface \&amp; Coatings Technology, (299), , 123-128.

http://dx.doi.org/10.1016/j.surfcoat.2016.04.076

Copyright: Elsevier

http://www.elsevier.com/

Postprint available at: Linköping University Electronic Press

http://urn.kb.se/resolve?urn=urn:nbn:se:liu:diva-130257

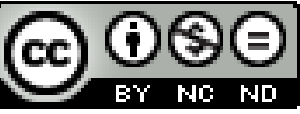




\section{Accepted Manuscript}

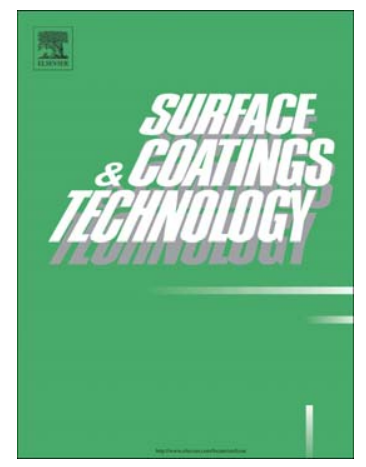

PII:

Reference:

doi: 10.1016/j.surfcoat.2016.04.076

SCT 21151

To appear in: $\quad$ Surface \& Coatings Technology

Received date: 11 January 2016

Revised date: $\quad 16$ March 2016

Accepted date: $\quad 30$ April 2016

Please cite this article as: Haicheng Yu, Xinkun Suo, Yongfeng Gong, Yuejin Zhu, Jie Zhou, Hua Li, Per Eklund, Qing Huang, $\mathrm{Ti}_{3} \mathrm{AlC}_{2}$ coatings deposited by liquid plasma spraying, Surface \& Coatings Technology (2016), doi: 10.1016/j.surfcoat.2016.04.076

This is a PDF file of an unedited manuscript that has been accepted for publication. As a service to our customers we are providing this early version of the manuscript. The manuscript will undergo copyediting, typesetting, and review of the resulting proof before it is published in its final form. Please note that during the production process errors may be discovered which could affect the content, and all legal disclaimers that apply to the journal pertain. 


\section{$\mathrm{Ti}_{3} \mathrm{AlC}_{2}$ coatings deposited by liquid plasma spraying}

Haicheng Yu ${ }^{\mathrm{a}, \mathrm{b}}$, Xinkun Suo ${ }^{\mathrm{a}}$, Yongfeng Gong ${ }^{\mathrm{a}}$, Yuejin Zhu ${ }^{\mathrm{b}}$, Jie Zhou ${ }^{\mathrm{a}}, \mathrm{Hua} \mathrm{Li}^{\mathrm{a}}$, Per Eklund $^{\mathrm{c}}$, Qing Huang ${ }^{\mathrm{a}, *}$

${ }^{\mathrm{a}}$ Engineering Laboratory of Specialty Fibers and Nuclear Energy Materials, Ningbo

Institute of Materials Engineering and Technology, Chinese Academy of Sciences, Ningbo 315201, Zhejiang, China

${ }^{\mathrm{b}}$ Department of Physics, Ningbo University, Ningbo 315211, Zhejiang, China

${ }^{\mathrm{c}}$ Thin Film Physics Division, Linköping University, IFM, 58183 Linköping, Sweden

*Corresponding author:

Tel: +86-574-86686062

E-mail: huangqing@nimte.ac.cn 


\section{Abstract}

$\mathrm{Ti}_{3} \mathrm{AlC}_{2}$ tends to partially decompose into $\mathrm{TiC}$ phase during deposition by traditional thermal spray techniques, preventing their use in surface anti-corrosion applications. Here, $\mathrm{Ti}_{3} \mathrm{AlC}_{2}$ coatings were synthesized using liquid plasma spraying (LPS). Although the average temperature of particles measured in LPS was higher than $2200 \mathrm{~K}$, enough to decompose $\mathrm{Ti}_{3} \mathrm{AlC}_{2}$ phase, the resulting sprayed $\mathrm{Ti}_{3} \mathrm{AlC}_{2}$ particles were intact. This is probably due to formation of a protective oxide on the surface in the high-temperature steam. The phase purity of $\mathrm{Ti}_{3} \mathrm{AlC}_{2}$ coating was high when using water as solvent, but low with a solvent of a mixture of water and alcohol. Different $\mathrm{pH}$ values of the solutions influence the phase purity of $\mathrm{Ti}_{3} \mathrm{AlC}_{2}$ coatings. The alkaline solutions show detrimental effect on the conservation of $\mathrm{Ti}_{3} \mathrm{AlC}_{2}$ phase. The mechanism of improved structural integrity of $\mathrm{Ti}_{3} \mathrm{AlC}_{2}$ phase at high temperature through LPS was revealed by microstructural and compositional analysis.

Key words: liquid plasma spraying, $\mathrm{Ti}_{3} \mathrm{AlC}_{2}$, decomposition 


\section{Introduction}

MAX phases, with a general formula $M_{n+1} A_{n}$ (M, early transition metal; $A$, an A-group element; X, carbon or nitrogen; $n, 1-3)$ [1] have attracted attention because of their unique advantage of combined metallic and ceramic merits [2, 3]. On one hand, MAX phases exhibit metallic properties, such as good electrical and thermal conductivity, good machinability, and excellent thermal shock resistance. On the other hand, they exhibit ceramic properties, such as good high temperature mechanical properties [4], and good oxidation resistance and corrosion resistance. Barsoum [5] listed potential applications as substitutes for machinable ceramics, wear and corrosion protection, heat exchangers, components where rotating parts are used, low friction applications based on basal plane lubricity [6] and ohmic contacts to $\mathrm{SiC}$ [7-9]. The archetypical MAX phase material, $\mathrm{Ti}_{3} \mathrm{AlC}_{2}$, is composed of hexagonal layers of $\mathrm{Al}$ separated by the layers of edge-sharing Ti-C. It is considered as a candidate for cladding tube coating materials in nuclear application owing to its good irradiation resistance [10] and good oxidation resistance [11-13].

In order to enable applications in the above fields, several synthesis techniques for MAX phase films have been reported such as chemical vapor deposition (CVD) [14-16], solid state reaction [8, 17,18], physical vapor deposition (PVD) by cathodic arc [19-21] and magnetron sputtering [22, 23]. All these methods present many advantages in fabricating MAX phases, such as ohesion, good compactness, controllable element ratio, and the possibility to synthesize multilayer coatings [1]. However, these processes also have some limitations. For example, a high process 
temperature $\left(900^{\circ} \mathrm{C}\right)$ is necessary to activate the chemical reactions in CVD [19]. Sputter-deposition allows for synthesis of MAX phases at lower temperature than CVD, but typically still requires a deposition temperature of $700^{\circ} \mathrm{C}$ or more [1]. In some circumstances, the preparation temperature should be kept low so as not to damage the substrates, especially during the deposition of coatings on steel or other temperature-sensitive substrates [24]. Cold spraying can maintain the integrity of $\mathrm{Ti}_{3} \mathrm{AlC}_{2}$ phase because of its moderate operation temperature [25-27]. Rech et al. [25] and Gutzmann et al. [26] have fabricated MAX phase coatings using cold spraying. However, because of the poor plasticity of $\mathrm{Ti}_{3} \mathrm{AlC}_{2}$, broken particles and cracks were found in the coatings. Recently, thermal spraying has been utilized to fabricate MAX phase coatings [28-30]. The obvious advantage of thermal spraying process over other deposition techniques lies in the fact that the spray facility has no strict requirement on the atmosphere (vacuum or gas-protection) and industrial scale synthesis is readily achievable. However, current popular thermal spraying techniques, such as atmospheric plasma spraying (APS), high velocity oxy-fuel spraying (HVOF), are not much applied to synthesize $\mathrm{Ti}_{3} \mathrm{AlC}_{2}$ phase coatings because of the high flame temperature which tends to cause severe phase decomposition and/or oxidation of MAX phases [31]. $\mathrm{Ti}_{2} \mathrm{AlC}$, rather than $\mathrm{Ti}_{3} \mathrm{AlC}_{2}$, coatings have been fabricated by HVOF [29]. For bulk materials, at high temperature $\left(1550^{\circ} \mathrm{C}\right), \mathrm{Ti}_{3} \mathrm{AlC}_{2}$ phase tends to decompose while $\mathrm{Ti}_{2} \mathrm{AlC}$ experienced decomposition to a more limited extent [36]. Because of the lower thermal stability than $\mathrm{Ti}_{2} \mathrm{AlC}$, high-purity $\mathrm{Ti}_{3} \mathrm{AlC}_{2}$ coatings have not been synthesized by HVOF. It can be concluded that the remaining amount of the 
$\mathrm{Ti}_{3} \mathrm{AlC}_{2}$ phase is low for APS and HVOF.

Another new thermal spraying technology is liquid plasma spraying (LPS). Unlike traditional air plasma spraying, LPS employs a liquid flow to feed powder into heat source instead of the carrier gas. This change bypasses the heating step for the powder by the plasma torch, thus enabling the deposition of thermally-sensitive coatings [32]. Many researchers have used this method to fabricate thermal barrier coatings [33]. However, no liquid plasma sprayed MAX coatings have been reported until now.

Therefore, the aim of this work is to investigate the feasibility of fabricating $\mathrm{Ti}_{3} \mathrm{AlC}_{2}$ coating from aqueous media using liquid plasma spraying. In order to obtain high purity coatings, a stable aqueous suspension containing $\mathrm{Ti}_{3} \mathrm{AlC}_{2}$ was prepared by adjusting the $\mathrm{pH}$ values. The deposition mechanism of MAX phase deposited using LPS was also discussed.

\section{Experimental details}

(1) Materials

According to the procedure in reference [34], $\mathrm{Ti}_{3} \mathrm{AlC}_{2}$ powders were synthesized by spark plasma sintering in our laboratory, and then grinded to break up the agglomerated materials. The particles with a size distribution from 1 to $100 \mu \mathrm{m}(30 \%$ of particles are smaller than $8.8 \mu \mathrm{m}$, and $80 \%$ of particles are smaller than $39.9 \mu \mathrm{m}$ ) were used as raw materials for atmospheric plasma spraying and liquid plasma spraying. 304 stainless steel plates with a dimension of $20 \times 15 \times 2 \mathrm{~mm}^{3}$ were used as substrate. The substrates were sand-blasted to remove the oxides and cleaned with ethanol before deposition. 
(2) $\mathrm{Ti}_{3} \mathrm{AlC}_{2}$ suspension preparation and liquid spraying parameters

The suspensions were prepared by adding $10 \mathrm{wt} \% \mathrm{Ti}_{3} \mathrm{AlC}_{2}$ particles in deionized water.

The mixture of deionized water and alcohol with the ratio of 1:1 was also used at the same content of $\mathrm{Ti}_{3} \mathrm{AlC}_{2}$ particles. The $\mathrm{pH}$ was adjusted by nitric acid $\left(\mathrm{HNO}_{3}\right)$ and sodium hydroxide $(\mathrm{NaOH})$.

A plasma spray system (APS-2000, Sulzer Metco) was used to fabricate $\mathrm{Ti}_{3} \mathrm{AlC}_{2}$ coatings. The spraying distance from the outlet to the substrate was set as $100 \mathrm{~mm}$ and the power was $15 \pm 0.5 \mathrm{~kW}$. For APS coatings, an F4 torch was utilized using an $\mathrm{Ar} / \mathrm{H}_{2}$ plasma gas mixture. The F4 torch is a commonly used torch in plasma spraying. Details of the F4 torch can be found in reference [35]. The gun velocity was $0.25 \mathrm{~m} / \mathrm{s}$. The same plasma spray system was used to produce both type of the coatings.

A system which detects the velocity and temperature of sprayed particles (DPV) was used to monitor the temperatures of the particles passing through the monitored surface. The distance from outlet to the temperature monitoring instrument was set to $100 \mathrm{~mm}$.

\section{(3) Characterization}

The X-ray diffraction (XRD) patterns of powders and coatings were acquired in a diffractometer (D8 Advance, Bruker AXS, Germany) with $\mathrm{Cu}$ K $\alpha$ radiation. The $2 \theta$ range, collection time per step and step size were set to $5^{\circ}-90^{\circ}, 0.2 \mathrm{~s}$ and $0.02^{\circ}$, respectively. The surface and cross section were observed using scanning electron microscopy equipped with an energy-dispersive X-ray spectrometer (SEM-EDS, Quanta FEG 250). The voltage and spot size in SEM were $15 \mathrm{kV}$ and 3.5, respectively. Quantitative phase analysis was conducted by means of the Rietveld analysis (TOPAS 
software). The peak shape parameters are FPA (Fundamental Parameters Approach). The $2 \theta$ range is $5^{\circ}-90^{\circ}$ during Rietveld analysis. Raman (Renishaw inVia Reflex) spectroscopy was used to detect the type of bonding, in the wavenumber range from 50 $\mathrm{cm}^{-1}$ to $1800 \mathrm{~cm}^{-1}$. The Nd:YAG laser was focused to a spot size of $\sim 1 \mu \mathrm{m}$ with an incident power of $6 \mathrm{~mW}$. DPV was used to test temperature and velocity of particles in APS and LPS process. Surface profiler (Alpha-step, KCA Tencor) was used to determine the roughness of $\mathrm{Ti}_{3} \mathrm{AlC}_{2}$ coating. The scan length and time was $500 \mu \mathrm{m}$ and $10 \mathrm{~s}$, respectively.

\subsection{Phase composition and morphologies of the sprayed powders}

XRD analysis was performed in order to investigate the phase transformation of the feedstock powder during deposition. Fig. 1a shows the XRD patterns of feedstock powder and as-sprayed powders using APS and LPS approaches, respectively. The feedstock powders (bottom in Fig. 1a) contained the $\mathrm{Ti}_{3} \mathrm{AlC}_{2}$ phase in majority (93.2\%) and also a small amount of TiC phase $(6.8 \%)$. After deposition by traditional APS (second from bottom in Fig. 1a), TiC phase became predominant in the coating, and most of the $\mathrm{Ti}_{3} \mathrm{AlC}_{2}$ phase had been depleted, which suggests that the $\mathrm{Ti}_{3} \mathrm{AlC}_{2}$ phase decomposed heavily due to the high temperature of the plasma torch. Only $20 \%$ of feedstock powders remained in the original phase, while others decomposed and oxidized into $\mathrm{Ti}_{2} \mathrm{AlC}, \mathrm{TiC}, \mathrm{Al}_{2} \mathrm{O}_{3}$ and $\mathrm{TiO}_{2}$. This result is in agreement with others [31]. The average temperature of particles in APS was higher than $2500 \mathrm{~K}$ as determined by the DPV temperature monitoring instrument. This temperature is much higher than 
$\mathrm{Ti}_{3} \mathrm{AlC}_{2}$ decomposition temperature $\left(1300^{\circ} \mathrm{C}\right)[36]$.

According to the XRD pattern of LPS coatings deposited with a mixture of water and alcohol (with the ratio of 1:1), most of the $\mathrm{Ti}_{3} \mathrm{AlC}_{2}$ decomposed (second from top in Fig. 1a). During this spraying process, a flame on the substrate could be observed optically. The flame should be caused by the burning of alcohol, which implies high temperature under these circumstances. However, in aqueous LPS, no flame could be observed. Compared with aqueous LPS, the flame would impart additional heat to cause the decomposition of $\mathrm{Ti}_{3} \mathrm{AlC}_{2}$ rather than protect $\mathrm{Ti}_{3} \mathrm{AlC}_{2}$ from decomposition. However, in the coating sprayed by aqueous LPS (with only deionized water as solvent) technique, the $\mathrm{Ti}_{3} \mathrm{AlC}_{2}$ phase was preserved (top in Fig. 1a). There is no obvious difference in the XRD patterns when compared with the raw powder. The number of peaks and the intensities of peaks are similar. As indicated by the vertical lines (Fig. 1a), the main characteristic peaks of $\mathrm{Ti}_{3} \mathrm{AlC}_{2}(2 \theta=9.517$ and 39.037) are strong for coatings synthesized by aqueous LPS. The phase-purity of $\mathrm{Ti}_{3} \mathrm{AlC}_{2}$ in the LPS coating was calculated, and the result shows that the percentage of $\mathrm{Ti}_{3} \mathrm{AlC}_{2}$ phase in aqueous LPS coatings was $84.5 \%$, which is considerably higher than what has been achieved by traditional thermal spraying [31]. The average velocity of the particles in LPS is $90 \mathrm{~m} / \mathrm{s}$. Another interesting observation is that no $\mathrm{TiO}_{2}$ phase was found in the XRD pattern of aqueous LPS coatings. This is in good agreement with previous work [37, 38], where the early stages of oxidation of $\mathrm{Ti}_{3} \mathrm{AlC}_{2}$ were investigated at $1373 \mathrm{~K}$ and $773 \mathrm{~K}$. In our experiment, the spraying time was extremely short $\left(\sim 10^{-3} \mathrm{~s}\right)$ and the temperature was much higher than $1373 \mathrm{~K}$. In addition, the lack of observed $\mathrm{TiO}_{2}$ may be attributed to 
the different nucleation and growth rate of $\mathrm{Al}_{2} \mathrm{O}_{3}$ and $\mathrm{TiO}_{2}$ as a function of the temperature $[12,13]$. Low temperature facilitates the preferential nucleation of $\mathrm{TiO}_{2}$, while at high temperature, the nucleation of $\mathrm{Al}_{2} \mathrm{O}_{3}$ is preferred over $\mathrm{TiO}_{2}$. In LPS process, the temperature is higher than $2200 \mathrm{~K}$ which facilitates the nucleation of alumina. No $\mathrm{TiO}_{2}$ could be found in the XRD patterns.

In order to see whether $\mathrm{TiO}_{2}$ formed in the aqueous LPS coatings, Raman spectroscopy was used, as shown in figure $1 \mathrm{~b}$. A Raman mode at $400 \mathrm{~cm}^{-1}$ is seen in the spectra, which is identified as rutile [39]. The rutile is presumably not observed in XRD because it is too fine-grained and/or has low phase content. Apart from $\mathrm{TiO}_{2}$ (vary from 100 $\mathrm{cm}^{-1}$ to $1000 \mathrm{~cm}^{-1}$ ), two vibrational modes at $270 \mathrm{~cm}^{-1}$ and $610 \mathrm{~cm}^{-1}$ which are identified as intrinsic vibrational modes of $\mathrm{Ti}_{3} \mathrm{AlC}_{2}$ [40] were detected. Some vibrational modes of $\mathrm{Ti}_{3} \mathrm{AlC}_{2}$ (there are six in total [40]) are not observed in our Raman spectroscopy results. The reason may be that the structure of $\mathrm{Ti}_{3} \mathrm{AlC}_{2}$ experienced some disorder, and that some of the Raman peaks are quite weak [41].

Additional peaks in the spectrum of coating appeared at 1320 and $1580 \mathrm{~cm}^{-1}$. These peaks could be distinguished as graphite band ( $\mathrm{G}$ band) and disordered/nanocrystalline carbon band (D band) [42, 43], which demonstrates the formation of carbon after LPS. This result is in agreement with references $[44,45]$. The affinity of metals to oxygen is higher than that of carbon [44], resulting in the formation of metallic oxides and the survival of carbon from oxidation. Similarly, carbon is present after hydrothermal oxidation and air oxidation of transition metal carbides [45]. But in this Raman spectroscopy, the intensity of the D and G bands was low, which means low 
free-carbon content in the coatings. Because of the reaction between water vapor and carbon, the content of remaining carbon should be in accordance with these Raman results. According to the reference [46,47], $\mathrm{CO}_{2}$ possesses higher partial pressures than $\mathrm{CO}$ at any temperature. At high temperature (higher than $500^{\circ} \mathrm{C}$ ), the partial pressure of $\mathrm{H}_{2}$ is far higher than $\mathrm{CH}_{4}$. In the LPS process, the average temperature is higher than $2200 \mathrm{~K}$ and the water vapor is abundant which all facilitate the formation of $\mathrm{CO}_{2}$ and $\mathrm{H}_{2}$.

Surface morphologies of powders which were sprayed into liquid nitrogen by APS and LPS are presented in Fig. 2a to 2d. As shown in Fig. 2a, the morphology of the feedstock powders is irregular. In addition, small submicron-scale chips can be found on the particle surface. Compared with feedstock powders, some spherical particles which indicated the decomposition of $\mathrm{Ti}_{3} \mathrm{AlC}_{2}$ occurred in the APS process (shown in Fig. 2b). Additionally, newly-occurring phases in XRD patterns of APS coating verified the decomposition behavior. The high temperature caused the decomposition of $\mathrm{Ti}_{3} \mathrm{AlC}_{2}$ and then remelted, forming spherical particles. EDS of the spherical particle surface and cross-section (as seen in Table 2) was applied to analyse the composition of these spherical particles. The result is that the constituent of this spherical particle is a mixture of titanium oxides and aluminium oxides.

Fig. 2c shows the morphologies of particles sprayed into liquid nitrogen by aqueous LPS. It presents a similar morphology to the feedstock particles which implies high content of retained $\mathrm{Ti}_{3} \mathrm{AlC}_{2}$. According to the XRD pattern of aqueous LPS and SEM micrograph (Fig. 2c), the $\mathrm{Ti}_{3} \mathrm{AlC}_{2}$ content and morphology is consistent with feedstock 
powders. Only tiny amounts of spherical particles could be found in aqueous LPS powders. As the solvent was a mixture of water and alcohol with the volume ratio of 1:1, the morphologies were significantly different from that of feedstock powders. In this spraying condition, some spherical particles occurred and the edges of particles became smooth and diffuse, indicating that the temperature was high enough to cause $\mathrm{Ti}_{3} \mathrm{AlC}_{2}$ decomposition. The difference between these methods is mainly the $\mathrm{Ti}_{3} \mathrm{AlC}_{2}$ particle temperature, which determines the decomposition of $\mathrm{Ti}_{3} \mathrm{AlC}_{2}$. Considering all of this, deionized water was used as solvent in the following experiments.

\subsection{Effect of solution characteristics on fabrication of $\mathrm{Ti}_{3} \mathrm{AlC}_{2}$ coatings}

As is known, $\mathrm{Ti}_{3} \mathrm{AlC}_{2}$ is more stable in basic solution than in acidic solution [48]. However, in the LPS process, circumstances differ greatly from the situation in a static solution. For example, the processing temperature is high. Therefore, it is necessary to know the influence of $\mathrm{pH}$ value of aqueous solution using LPS. Accordingly, $\mathrm{pH}$ values of the liquid were adjusted by $\mathrm{NaOH}$ and $\mathrm{HNO}_{3}$, and the effect of solution characteristics on the microstructure of $\mathrm{Ti}_{3} \mathrm{AlC}_{2}$ coatings was investigated. XRD patterns of $\mathrm{Ti}_{3} \mathrm{AlC}_{2}$ coatings are shown in Fig. 3. The evolution of phase content in coatings as a function of $\mathrm{pH}$ values of liquid solutions was also studied, and the result is summarized in Table 1. The content of $\mathrm{Ti}_{3} \mathrm{AlC}_{2}$ shows little divergence in acidic solution and neutral solution, respectively. $\mathrm{Ti}_{3} \mathrm{AlC}_{2}$ is the predominately phase in these coatings.

However, it can be found that the content of $\mathrm{Ti}_{3} \mathrm{AlC}_{2}$ phase remaining in the coatings deposited using alkaline solution was lower than that in coatings deposited using acidic 
and neutral solution. Besides water vapor, hydroxyl ion in alkaline solution can also react with $\mathrm{Ti}_{3} \mathrm{AlC}_{2}$. As aluminium can be leached out from $\mathrm{Ti}_{3} \mathrm{AlC}_{2}$, it can immediately react with $\mathrm{OH}^{-}$which makes more $\mathrm{Ti}_{3} \mathrm{AlC}_{2}$ will be decomposed. This explanation may account for the influence of $\mathrm{pH}$ values.

\subsection{Protective mechanism of $\mathrm{Ti}_{3} \mathrm{AlC}_{2}$ coatings in aqueous LPS}

Apart from the evaporation of water which absorbed heat from the spraying, other factors might play a role in protecting $\mathrm{Ti}_{3} \mathrm{AlC}_{2}$ from heavy decomposition. The average temperature of particles in aqueous LPS measured by DPV2000 was $2261 \mathrm{~K}$, which exceeded the decomposition temperature of $\mathrm{Ti}_{3} \mathrm{AlC}_{2}$ particles. The average temperature of particles in APS is $2615 \mathrm{~K}$. These two temperatures exceeded the decomposition temperature, but the results exhibited significant divergence. The composition of in-flight $\mathrm{Ti}_{3} \mathrm{AlC}_{2}$ particles prior to impact to substrates was also investigated in order to reveal the deposition mechanism of aqueous LPS coatings. Ti-Al bonds in $\mathrm{Ti}_{3} \mathrm{AlC}_{2}$ phase are relatively weak and the Al element is highly active, which is characterized by low vacancy formation energy and vacancy migration energy [50, 51]. The layered structure is favorable for the fast diffusion of water vapor or/and oxygen in the grains, which facilitates the rapid reaction of aluminium.

The reaction between $\mathrm{Al}$ and water vapor or/and oxygen may occur at the surface. The in-diffusion rate of water vapor and oxygen and out-diffusion rate of aluminium in alumina is slow. Besides the slow diffusion rate, the whole time of spraying process is extremely short. Therefore, the formed alumina attached to the surface plays an important role in protecting $\mathrm{Ti}_{3} \mathrm{AlC}_{2}$ from heavy decomposition. The absence of Raman 
signal from the coatings is due to the screening effect of thin outer layer of titania phase. In order to support our discussion, cross sections of collected $\mathrm{Ti}_{3} \mathrm{AlC}_{2}$ particle were observed. The $\mathrm{Ti}_{3} \mathrm{AlC}_{2}$ powders were sprayed into liquid nitrogen, and then dried. As shown in Fig. 4, the contents of $\mathrm{Al}$ and $\mathrm{O}$ elements suddenly increased near the surface of the particles. Meanwhile, the Ti elemental content greatly decreased at the surface, which suggested that alumina formed outside particles in water vapor.

\subsection{Microstructure of $\mathrm{Ti}_{3} \mathrm{AlC}_{2}$ coatings}

The $\mathrm{Ti}_{3} \mathrm{AlC}_{2}$ coatings were prepared using aqueous LPS. The cross section microstructure and surface morphology of coatings are shown in Fig. 5a and 5b, respectively. In Fig. 5a, it can be seen that the thickness of the coatings ranged from 10 $\mu \mathrm{m}$ to $20 \mu \mathrm{m}$, and no cracks could be found in the coating. The crack observed in the cross section micrograph is at the interface between the coating and the epoxy resin. Some pores can be observed in the cross-section (Fig. 5a). Fig. 5b shows that the particles on surface of the coatings exhibit a similar morphology to the feedstock particles. Compared with the morphology of particles sprayed in liquid nitrogen (Fig. 2c), the morphology of particles in the corresponding coating (Fig. 5b) is similar. Their morphologies are all consistent with that of the raw powder.

From the observed surface morphology of coatings, it could also be found that the coatings exhibit a large roughness. Some cavities smaller than $4 \mu \mathrm{m}$ was also found on the surface of coatings. The roughness of the $\mathrm{Ti}_{3} \mathrm{AlC}_{2}$ coating determined by a surface profiler varies from less than $1 \mu \mathrm{m}$ to $8 \mu \mathrm{m}$. Because of the low densification, the adhesion could not be obtained by pull-out test. 
As a concluding point, LPS is a feasible method to synthesize $\mathrm{Ti}_{3} \mathrm{AlC}_{2}$ coatings, but also leaves space for the further improvement (techniques to reduce the residual pores and roughness of the coatings). The drop of velocity of $\mathrm{Ti}_{3} \mathrm{AlC}_{2}$ particles due to the evaporation of solvent during LPS process is the key factor. In future work, the protection of $\mathrm{Ti}_{3} \mathrm{AlC}_{2}$ particles by steam and the minimization of kinetic-energy-loss due to solvent evaporation, should be balanced to achieve dense coating fabrication.

\section{Conclusions}

Liquid plasma spraying was used to fabricate $\mathrm{Ti}_{3} \mathrm{AlC}_{2}$ coatings, and the influences of $\mathrm{pH}$ value and acid property on microstructures of coatings were evaluated. The main result can be drawn:

(1) The fabrication of $\mathrm{Ti}_{3} \mathrm{AlC}_{2}$ coatings with high $\mathrm{Ti}_{3} \mathrm{AlC}_{2}$ content using liquid plasma spraying is feasible.

(2) The $\mathrm{pH}$ value of solutions plays an important role for the purity of $\mathrm{Ti}_{3} \mathrm{AlC}_{2}$ coatings. The content of $\mathrm{Ti}_{3} \mathrm{AlC}_{2}$ in coating is high when the solvent is acidic and neutral solution. The content of $\mathrm{Ti}_{3} \mathrm{AlC}_{2}$ phase remained in the coatings deposited using alkaline solution was lower than that in acidic and neutral solution.

(3) The high content of $\mathrm{Ti}_{3} \mathrm{AlC}_{2}$ phase in coatings is attributed to the formation of alumina protective phase during the decomposition process of $\mathrm{Ti}_{3} \mathrm{AlC}_{2}$ phase, which impedes further decomposition.

\section{Acknowledgements}

The present work was supported by the National Natural Science Foundation of China (Grant No. 91226202 and 91426304), the "Strategic Priority Research Program" of the 
Chinese Academy of Sciences (Grant No. XDA 02040105 and XDA03010305), and the Major Project of the Ministry of Science and Technology of China (Grant No.2015 ZX06004-001). P. E. also acknowledges support from the Swedish Foundation for Strategic Research (SSF) through the Future Research Leaders 5 program and the Synergy Grant FUNCASE. 


\section{References}

[1] P. Eklund, M. Beckers, U. Jansson, H. Högberg and L. Hultman, The Mn+1AXn phases: materials science and thin film processing, Thin Solid Films, 518 (2010) 1851-1878.

[2] M.W. Barsoum, N. Tzenov, A. Procopio, T. El-Raghy, M. Ali, Oxidation of Tin+1AlXn ( $\mathrm{n}=1-3$ and $\mathrm{X}=\mathrm{C}, \mathrm{N})$ - II. Experimental results, J Electrochem Soc, 148 (2001) C551-C562.

[3] M.W. Barsoum, Oxidation of Tin+1AlXn ( $\mathrm{n}=1-3$ and $\mathrm{X}=\mathrm{C}, \mathrm{N})$ - I. Model, J Electrochem Soc, 148 (2001) C544-C550.

[4] M. W. Barsoum, M. Radovic, Elastic and Mechanical Properties of the MAX Phases, Annu. Rev. Mater. Res. , 41 (2011) 195-227.

[5] M.W. Barsoum, The $\mathrm{M}(\mathrm{N}+1) \mathrm{AX}(\mathrm{N})$ phases: A new class of solids; Thermodynamically stable nanolaminates, Prog Solid State Ch, 28 (2000) 201-281.

[6] Z.M. Sun, Progress in research and development on MAX phases: a family of layered ternary compounds, International Materials Reviews, 56 (2011) 143-166.

[7] S. Tsukimoto, T. Sakai, M. Murakami, Electrical properties and microstructure of ternary Ge/Ti/Al ohmic contacts to p-type 4H-SiC, J Appl Phys, 96 (2004) 4976-4981.

[8] H. Fashandi, M. Andersson, J. Eriksson, J. Lu, K. Smedfors, C.M. Zetterling, A.L. Spetz, P. Eklund, Single-step synthesis process of Ti3SiC2 ohmic contacts on $4 \mathrm{H}-\mathrm{SiC}$ by sputter-deposition of Ti, Scripta Mater, 99 (2015) 53-56.

[9] K. Buchholt, R. Ghandi, M. Domeij, C.M. Zetterling, J. Lu, P. Eklund, L. Hultman, A.L. Spetz, Ohmic contact properties of magnetron sputtered Ti3SiC2 on n- and p-type 4H-silicon carbide, Appl Phys Lett, 98 (2011) 042108

[10] K.R. Whittle, M.G. Blackford, R.D. Aughterson, S. Moricca, G.R. Lumpkin, D.P. Riley, N.J. Zaluzec, Radiation tolerance of Mn+1AXn phases, Ti3AlC2 and Ti3SiC2, Acta Materialia, 58 (2010) 4362-4368.

[11] X.H. Wang, Y.C. Zhou, Oxidation behavior of Ti3AlC2 at $1000-1400{ }^{\circ} \mathrm{C}$ in air, Corros Sci, 45 (2003) 891-907.

[12] D.J. Tallman, B. Anasori, M.W. Barsoum, A Critical Review of the Oxidation of Ti2AlC, Ti3AlC2 and Cr2AlC in Air, Materials Research Letters, 1 (2013) 115-125.

[13] S. Basu, N. Obando, A. Gowdy, I. Karaman, M. Radovic, Long-Term Oxidation of 
Ti2AlC in Air and Water Vapor at 1000-1300 degrees C Temperature Range, J Electrochem Soc, 159 (2012) C90-C96.

[14] S. Jacques, H. Di-Murro, M.P. Berthet, H. Vincent, Pulsed reactive chemical vapor deposition in the C-Ti-Si system from H-2/TiCl4/SiCl4, Thin Solid Films, 478 (2005) $13-20$

[15] H. Fakih, S. Jacques, M.P. Berthet, F. Bosselet, O. Dezellus, J.C. Viala, The growth of Ti3SiC2 coatings onto $\mathrm{SiC}$ by reactive chemical vapor deposition using H-2 and TiCl4, Surface \& Coatings Technology, 201 (2006) 3748-3755.

[16] H. Fakih, S. Jacques, O. Dezellus, M.P. Berthet, F. Bosselet, M. Sacerdote-Peronnet, J.C. Viala, Phase equilibria and reactive chemical vapor deposition (RCVD) of Ti(3)SiC(2), J Phase Equilib Diff, 29 (2008) 239-246.

[17] B. Veisz, B. Pecz, Polarity dependent Al-Ti contacts to 6H-SiC, Applied Surface Science, 233 (2004) 360-365.

[18] S. Tsukimoto, K. Nitta, T. Sakai, M. Moriyama, M. Murakami, Correlation between the electrical properties and the interfacial microstructures of TiAl-based ohmic contacts to p-type 4H-SiC, J Electron Mater, 33 (2004) 460-466.

[19] J. Rosen, L. Ryves, P. Persson, M. Bilek, Deposition of epitaxial Ti 2 AlC thin films by pulsed cathodic arc, J Appl Phys, 101 (2007) 056101

[20] M.C. Guenette, M.D. Tucker, M. Ionescu, M.M.M. Bilek, D.R. McKenzie, Cathodic arc co-deposition of highly oriented hexagonal Ti and Ti2AlC MAX phase thin films, Thin Solid Films, 519 (2010) 766-769.

[21] A. Mockute, P.O.A. Persson, F. Magnus, A.S. Ingason, S. Olafsson, L. Hultman, J. Rosen, Synthesis and characterization of arc deposited magnetic (Cr,Mn)(2)AlC MAX phase films, Phys Status Solidi-R, 8 (2014) 420-423.

[22] O. Wilhelmsson, J.P. Palmquist, E. Lewin, J. Emmerlich, P. Eklund, P.O.A. Persson, H. Hogberg, S. Li, R. Ahuja, O. Eriksson, L. Hultman, U. Jansson, Deposition and characterization of ternary thin films within the Ti-Al-C system by DC magnetron sputtering, J Cryst Growth, 291 (2006) 290-300.

[23] D.P. Sigumonrong, J. Zhang, Y.C. Zhou, D. Music, J.M. Schneider, Synthesis and elastic properties of $\mathrm{V} 2 \mathrm{AlC}$ thin films by magnetron sputtering from elemental targets, J Phys D Appl Phys, 42 (2009) 185408

[24] Y. Liang, Z.Q. Sun, J.X. Chen, X.X. Liu, Y.C. Zhou, Electrophoretic Deposition of Ti3Si(Al)C-2 from Aqueous Suspension, J Am Ceram Soc, 93 (2010) 1916-1921. 
[25] S. Rech, A. Surpi, S. Vezzu, A. Patelli, A. Trentin, J. Glor, J. Frodelius, L. Hultman, P. Eklund, Cold-spray deposition of Ti2AlC coatings, Vacuum, 94 (2013) 69-73.

[26] H. Gutzmann, F. Gärtner, D. Höche, C. Blawert, T. Klassen, Cold spraying of Ti2AlC MAX-phase coatings, Journal of thermal spray technology, 22 (2013) 406-412.

[27] H. Assadi, F. Gartner, T. Stoltenhoff, H. Kreye, Bonding mechanism in cold gas spraying, Acta Materialia, 51 (2003) 4379-4394.

[28] V. Pasumarthi, Y. Chen, S.R. Bakshi, A. Agarwal, Reaction synthesis of Ti3SiC2 phase in plasma sprayed coating, J Alloy Compd, 484 (2009) 113-117.

[29] J. Frodelius, M. Sonestedt, S. Bjorklund, J.P. Palmquist, K. Stiller, H. Hogberg, L. Hultman, Ti(2)AlC coatings deposited by High Velocity Oxy-Fuel spraying, Surface \& Coatings Technology, 202 (2008) 5976-5981.

[30] J. Frodelius, E.M. Johansson, J.M. Cordoba, M. Oden, P. Eklund, L. Hultman, Annealing of Thermally Sprayed Ti2AlC Coatings, Int J Appl Ceram Tec, 8 (2011) 74-84.

[31] R. Trache, R. Puschmann, C. Leyens, L. Berger, B. Matthey, M. Herrmann, Thermally sprayed Ti3SiC2 and Ti2AlC MAX-phase coatings, Conference proceedings: Int. Thermal Spray Conf. (2013) 74-78

[32] H. Kassner, R. Siegert, D. Hathiramani, R. Vassen, D. Stoever, Application of suspension plasma spraying (SPS) for manufacture of ceramic coatings, Journal of Thermal Spray Technology, 17 (2008) 115-123.

[33] N. Schlegel, S. Ebert, G. Mauer, R. Vassen, Columnar-Structured Mg-Al-Spinel Thermal Barrier Coatings (TBCs) by Suspension Plasma Spraying (SPS), Journal of Thermal Spray Technology, 24 (2015) 144-151.

[34] W.B. Zhou, B.C. Mei, J.Q. Zhu, Fabrication of high-purity ternary carbide Ti3AlC2 by spark plasma sintering (SPS) technique, Ceram Int, 33 (2007) 1399-1402.

[35] J.F. Coudert, V. Rat, Influence of configuration and operating conditions on the electric arc instabilities of a plasma spray torch: role of acoustic resonance, Journal of Physics D: Applied Physics, 41 (2008) 205208.

[36] W.K. Pang, I.M. Low, B.H.O. Connor, A.J. Studer, V.K. Peterson, Z.M. Sun, J.P. Palmquist, Comparison of thermal stability in MAX 211 and 312 phases, Journal of Physics: Conference Series, 251 (2010) 012025-012029. 
[37] G.M. Song, Y.T. Pei, W.G. Sloof, S.B. Li, J.T.M. De Hosson, S. van der Zwaag, Early stages of oxidation of Ti3AlC2 ceramics, Mater Chem Phys, 112 (2008) 762-768.

[38] J. Frodelius, J. Lu, J. Jensen, D. Paul, L. Hultman, P. Eklund, Phase stability and initial low-temperature oxidation mechanism of Ti2AlC thin films, Journal of the European Ceramic Society, 33 (2013) 375-382.

[39] V. Swamy, Size-dependent modifications of the first-order Raman spectra of nanostructured rutile TiO(2), Phys Rev B, 77 (2008) 195414.

[40] V. Presser, M. Naguib, L. Chaput, A. Togo, G. Hug, M.W. Barsoum, First-order Raman scattering of the MAX phases: Ti2AlN, Ti2AlC0.5N0.5, Ti2AlC, (Ti0.5V0.5)2AlC, V2AlC, Ti3AlC2, and Ti3GeC2, J Raman Spectrosc, 43 (2012) $168-172$.

[41] D.D. Sun, A.G. Zhou, Z.Y. Li, L.B. Wang, Corrosion behavior of Ti3AlC2 in molten KOH at 700 degrees C, J Adv Ceram, 2 (2013) 313-317.

[42] N.S. Jacobson, Y.G. Gogotsi, M. Yoshimura, Thermodynamic and experimental study of carbon formation on carbides under hydrothermal conditions, J. Mater. Chem., 5 (1995) 595-601.

[43] E. Barringer, Z. Faiztompkins, H. Feinroth, T. Allen, M. Lance, H. Meyer, L. Walker, E. Lara - Curzio, Corrosion of CVD silicon carbide in $500 \mathrm{C}$ supercritical water, J Am Ceram Soc, 90 (2007) 315-318.

[44] S. Shimada, Oxidation and mechanism of single crystal carbides with formation of carbon, J Ceram Soc Jpn, 109 (2001) S33-S42.

[45] S. Shimada, Interfacial reaction on oxidation of carbides with formation of carbon, Solid State Ionics, 141 (2001) 99-104.

[46] H.B. Zhang, V. Presser, K.G. Nickel, C. Berthold, Y.C. Zhou, Hydrothermal Oxidation Behavior of Bulk Titanium Aluminum Carbide, J Am Ceram Soc, 94 (2011) 3460-3466.

[47] H.B. Zhang, X. Wang, K.G. Nickel, Y.C. Zhou, Experimental and thermodynamic study of the hydrothermal oxidation behavior of Ti3SiC2 powders, Scripta Mater, 59 (2008) 746-749.

[48] D. Li, Y. Liang, X.X. Liu, Y.C. Zhou, Corrosion behavior of Ti3AlC2 in NaOH and H2SO4, Journal of the European Ceramic Society, 30 (2010) 3227-3234. 
[49] L. He, Y. Zhou, Y. Bao, Z. Lin, J. Wang, Synthesis, physical, and mechanical properties of bulk Zr3Al3C5 ceramic, J Am Ceram Soc, 90 (2007) 1164-1170

[50] T. Liao, J.Y. Wang, Y.C. Zhou, First-principles investigation of intrinsic defects and (N, O) impurity atom stimulated Al vacancy in Ti2AlC, Appl Phys Lett, 93 (2008) 261911

[51] X.H. Wang, F.Z. Li, J.X. Chen, Y.C. Zhou, Insights into high temperature oxidation of Al2O3-forming Ti3AlC2, Corros Sci, 58 (2012) 95-103. 


\section{Figure captions:}

Fig. 1a XRD patterns of feedstock powder, APS coating, LPS coating (the solvent is a mixture of water and alcohol), aqueous LPS coating (the solvent is water). Fig.1b Raman spectra of $\mathrm{Ti}_{3} \mathrm{AlC}_{2}$ coatings synthesized by aqueous LPS.

Fig. 2 SEM micrographs (secondary electron images) of (a) feedstock powders, (b) APS powders, (c) LPS powders (the solvent is water), (d) LPS powders (the solvent is a mixture of water and alcohol)

Fig. $3 \mathrm{X}$-ray diffractogram from as-sprayed $\mathrm{Ti}_{3} \mathrm{AlC}_{2}$ coating with different $\mathrm{pH}$ values Fig. 4 Line scanning analysis of particle cross-section by LPS

Fig. 5 SEM micrographs (secondary electron images) of (a) cross section and (b) surface morphology of the $\mathrm{Ti}_{3} \mathrm{AlC}_{2}$ coating 


\section{Figure 1}
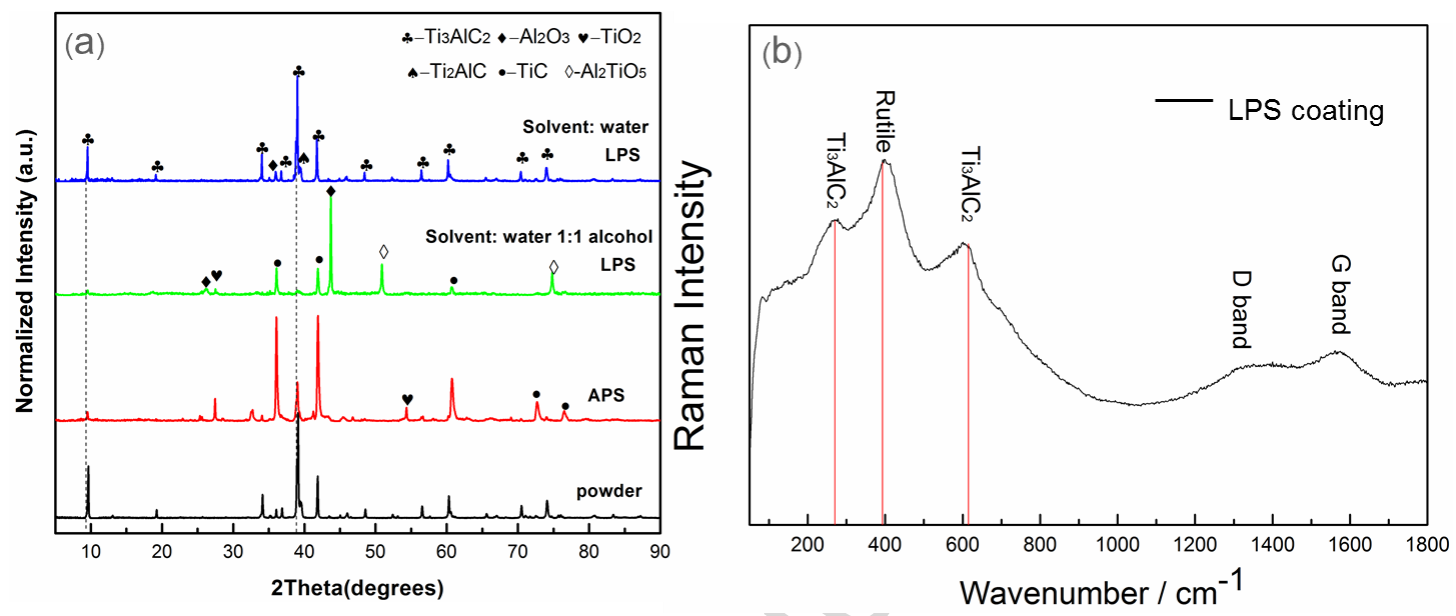
Figure 2

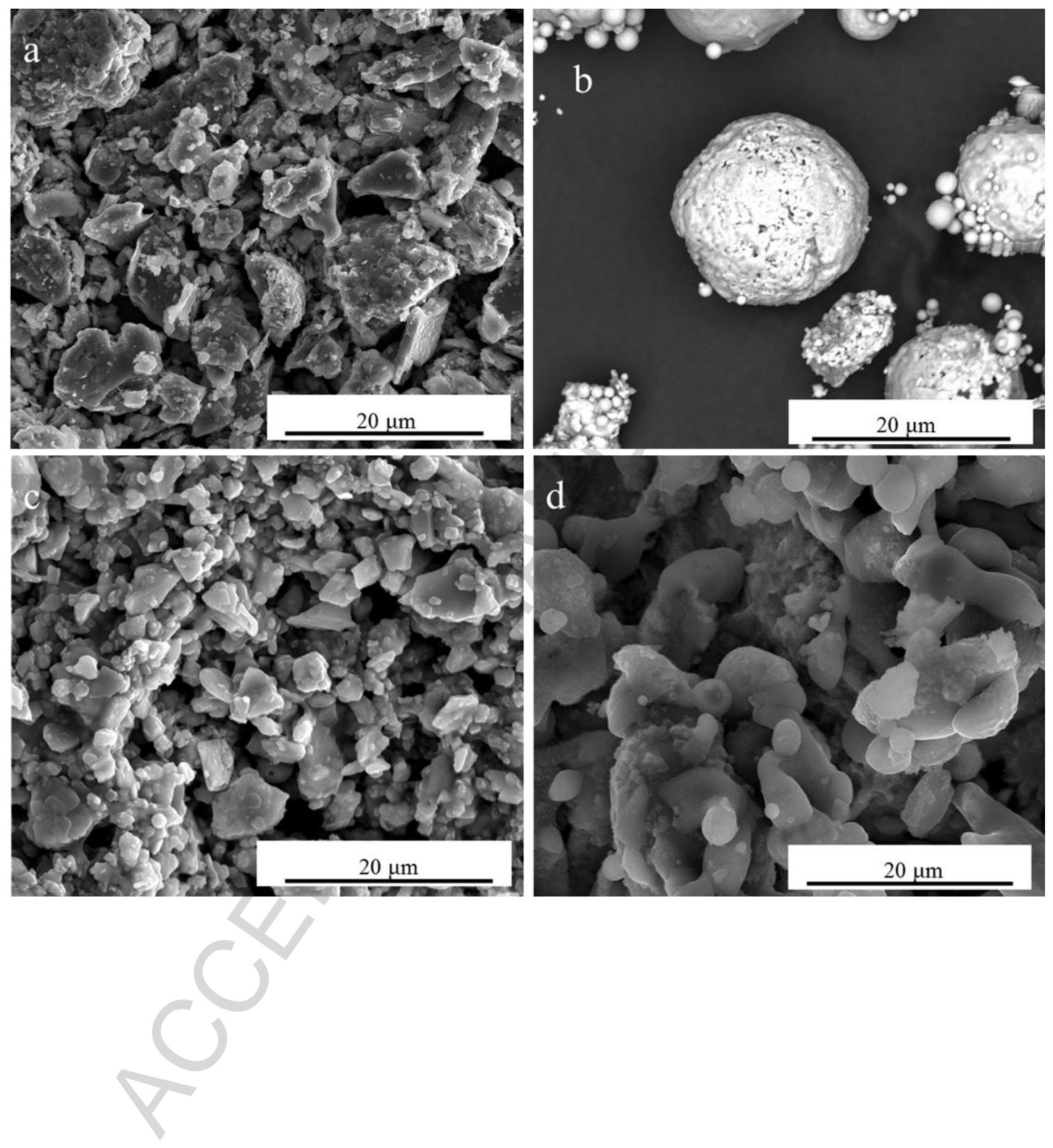


Figure 3

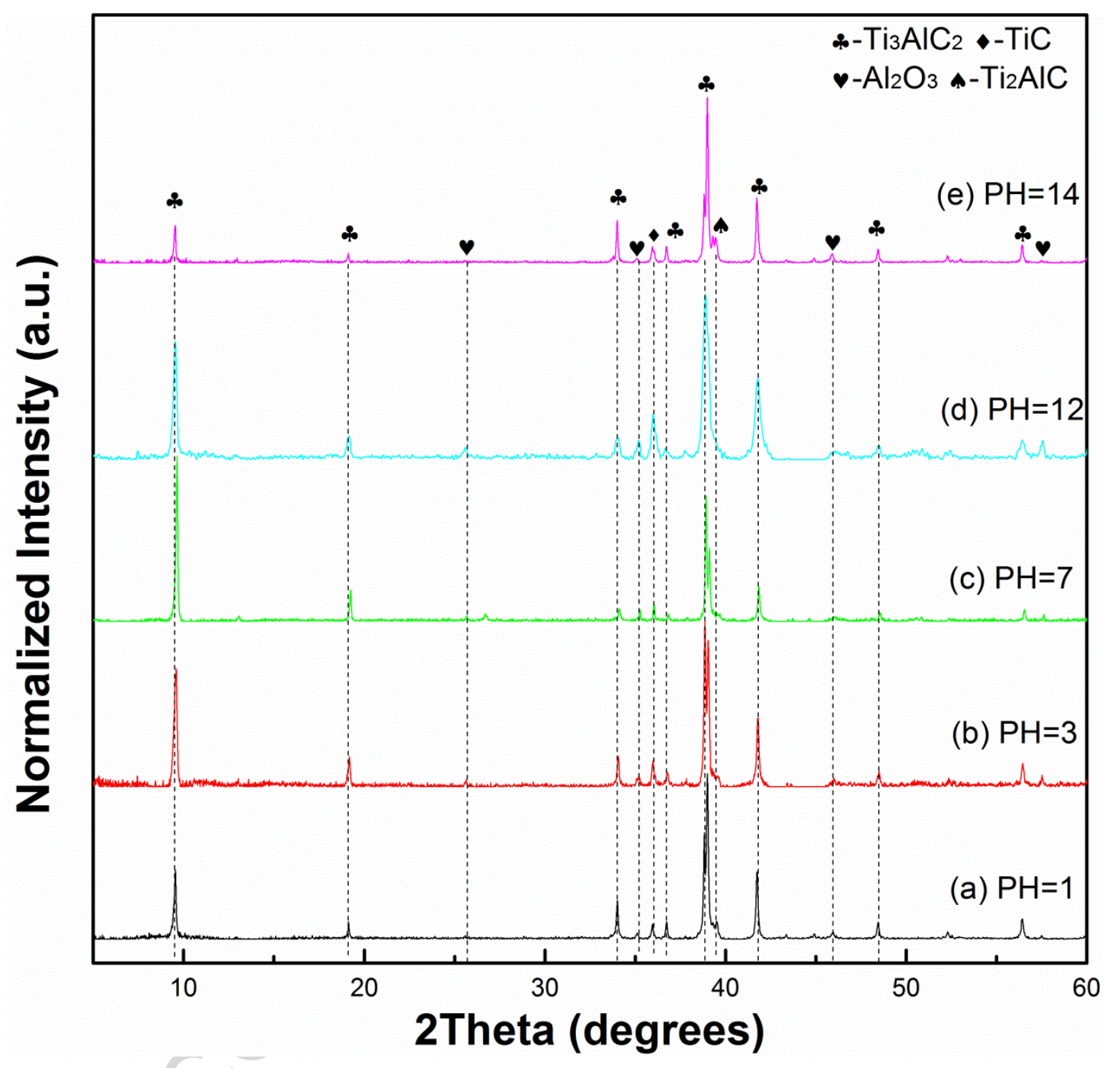


Figure 4

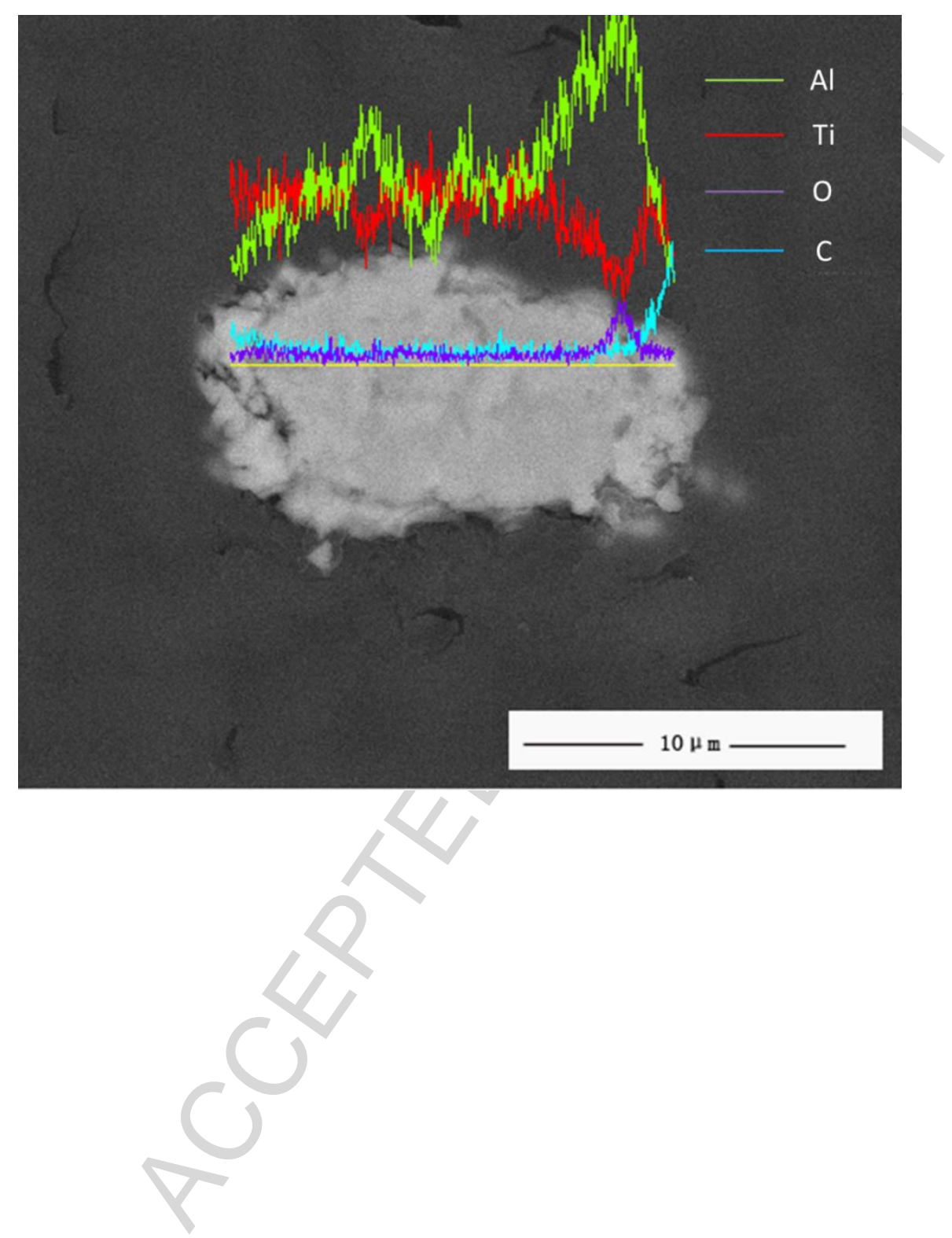




\section{Figure 5}

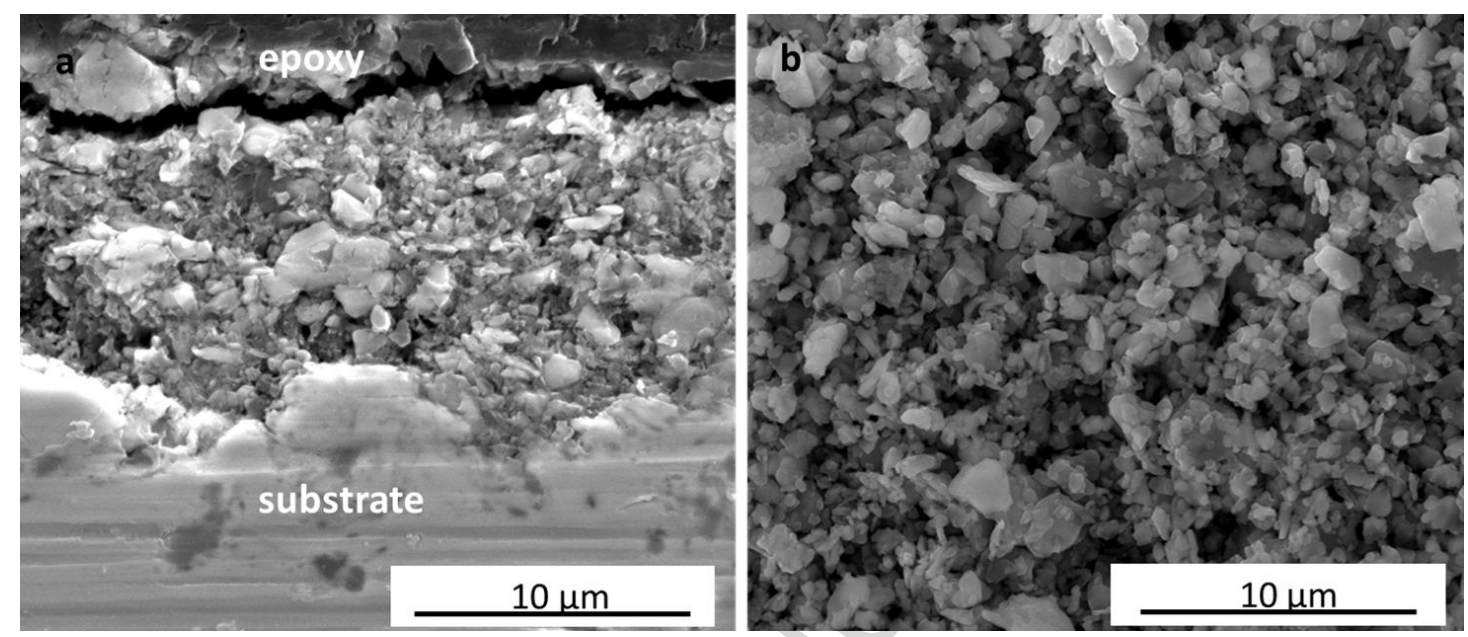


Table 1 The percentage of phases in coatings by aqueous LPS

\begin{tabular}{|c|c|c|c|c|c|c|}
\hline \multirow{2}{*}{$\mathrm{pH}$} & \multicolumn{4}{|c|}{ Phase Content } & \multirow{2}{*}{$\begin{array}{l}\text { Rwp[49] } \\
\text { (wt\%) }\end{array}$} & \multirow{2}{*}{$\chi^{2}$} \\
\hline & $\mathrm{Ti}_{3} \mathrm{AlC}_{2}$ & $\mathrm{Ti}_{2} \mathrm{AlC}$ & $\mathrm{Al}_{2} \mathrm{O}_{3}$ & $\mathrm{TiC}$ & & \\
\hline 1 & 82.56 & 0.87 & 10.9 & r & 7.678 & 1.57 \\
\hline 3 & 80.09 & 1.25 & 12.51 & & 5.897 & 1.39 \\
\hline 7 & 84.48 & 0.02 & 5.85 & & 8.897 & 1.44 \\
\hline 12 & 77.34 & 1.26 & 11.49 & 9.91 & 9.054 & 1.68 \\
\hline 14 & 74.32 & 1.22 & 13.27 & 11.19 & 8.750 & 1.70 \\
\hline
\end{tabular}

$\chi 2$ : the goodness -of-fit $\quad$ Rwp: R-weighted pattern 
Table 2 The element content of surface and cross section of spherical particle Estimated error $( \pm 1$ at $\%)$

\begin{tabular}{ccc}
\hline Element & surface & Cross section \\
\hline $\mathrm{C}$ & 14 & 6 \\
$\mathrm{O}$ & 61 & 67 \\
$\mathrm{Al}$ & 4 & 5 \\
$\mathrm{Ti}$ & 21 & 22 \\
\hline
\end{tabular}


Highlights

(1) High purity of $\mathrm{Ti}_{3} \mathrm{AlC}_{2}$ coatings were fabricated using liquid plasma spraying

(2) The effects of solution properties on coating microstructures were evaluated

(3) The deposition mechanism of liquid plasma sprayed $\mathrm{Ti}_{3} \mathrm{AlC}_{2}$ coatings was discussed 